\title{
特別講演
}

\section{Recent Developments in Neuropsychological Rehabilitation}

\author{
Barbara A. Wilson*
}

\section{Introduction}

Since I started working in the field of brain injury rehabilitation twenty seven years ago I have noticed several developments and these are almost certainly for the better. Not all are new developments as Poppelreuter was describing some of them as long ago as 1917. Indeed, the rehabilitation programmes set up for the German soldiers who survived gun shot wounds to the head in the first world war are better than many rehabilitation programmes in existence today. Nevertheless, the early twenty first century is an exciting time to be working in rehabilitation and the future looks promising. To my mind, the most important and influential developments in the past decade are those I list below.

1. Rehabilitation is now seen as a partnership between people with brain injury, their families and health service staff.

2. Goal planning is becoming increasingly established as one of the major methods for designing rehabilitation programmes.

3. Cognitive, emotional and psychosocial deficits are interlinked and all should be addressed in neuropsychological treatment programmes.

4. Technology is playing (and will continue to play) an increasing part in the understanding of brain injury and in enabling brain injured people to compensate for their difficulties.

5. Rehabilitation is beginning to take place in intensive care, it is not solely for those people who are medically stable.

6. There is a growing belief that neuropsychological rehabilitation is a field that needs a broad theoretical base incorporating frameworks, models and methodologies from a number of different fields.

\section{Rehabilitation as a partnership between clients, families and health care staff}

In 1991, McLellan defined rehabilitation as a two-way process between people disabled by injury or disease, health care staff and members of the wider community. He believed that, unlike surgery or drugs, rehabilitation is not something we 'do' to people or 'give' to people. Instead, the disabled person is part of a twoway interactive process. This represented a move forward. For many years the person with disability was told what to expect in and from rehabilitation, the rehabilitation staff determined what areas to work on, what

$\dagger$ This article is based on a chapter entitled "The future of neuropsychological rehabilitation" first published in Wilson B. A (2003) Neuropsychological Rehabilitation : Theory and Practice. Swets and Zeitlinger, Lisse, The Netherlands. Reproduced with permission. 
goals to set, what was achievable and what was not. Sometime in the 1980's, the philosophy began to change - at least in some centres-so that in many rehabilitation programmes today, clients and families are asked about their expectations, rehabilitation goals are discussed and negotiated between all parties involved. The focus of treatment is on improving aspects of everyday life and, as Ylvisaker and Feeney (2000) say, "rehabilitation needs to involve personally meaningful themes, activities, settings and interactions". Wilson, Evans, and Keohane (2002) describe the treatment of a man with both a stroke and a head injury. One of this man's goals was to fly his model helicopter again. An important goal for him, it probably would never have been considered thirty years ago. Evans (2003) illustrates this approach in his case description of David, a man with attention and planning problems following a stroke. Tate, Strettles, and Osoteo (2003) also imply the importance of partnership in the descriptions of their service for people with brain injury and Clare (2003) describes how people with dementia select their own targets for treatments. This is a much healthier state of affairs than providing clients with experimental or artificial material to work on. Motivation is likely to be increased because all are working on real life problems and generalisation difficulties are avoided.

\section{Goal planning as a means of designing rehabilitation programmes}

One of the ways of ensuring a client-centred approach and achieving a genuine partnership is to use goal planning to devise treatment programmes. Goal planning allows treatment to be tailored to the individual needs of people with brain injuries and their families. Although this approach is not new and has been used in rehabilitation settings for a number of years and with a number of diagnostic groups, including people with brain injury, in the last 10 years more and more centres have adopted this method to plan rehabilitation. Goal planning makes sense to staff, to clients and to families.

Houts and Scott (1975) suggest there are five principles involved in goal planning. First, involve the patient. Second, set reasonable goals. Third, describe the patient's behaviour when the goal is reached. Fourth, set a deadline. Fifth, spell out the method so that anyone reading it would know what to do. McMillan and Sparkes (1999) add to this list. They say that goals should be client-centred, they should be realistic and potentially attainable during admission, they should be clear and specific, have a definite time deadline and be measurable. They also say that long-term and short-term goals are required. Long-term goals usually refer to disabilities and handicaps as the purpose of rehabilitation is to improve everyday functioning and these goals should be achieved by the time of discharge from the centre. Short-term goals are the steps required to achieve the long-term goals.

The process of goal planning involves allocation of a chairperson, formulation of a plan of assessment, having goal planning meetings, the drawing up of a problem list and plans of action, and the recording of whether or not the goals are achieved (or, if not achieved why not). The main advantages of this system are first, the aims of admission are made clear and explicitly documented; second, patients or clients, their families and carers are all involved; third, some outcome measures are incorporated into the treatment programmes and fourth, the artificial distinctions between outcomes and patient/client activities are removed. Although, in principle, it is possible to make the goals too easy, there are ways round this. McMillan and Sparkes (1999) believe one can avoid making goals too easy through staff training and experience while Malec (1999) describes goal attainment scaling to allow a measure of comparability between different goals. It is probably true to say that goal planning is one of the most sensible outcome measures but should be used alongside other more standardised measures such as measures of handicap, mood, psychosocial functioning 
and demographics. Wilson et al. (2002) provide a fairly detailed description of goal planning used in the successful treatment of a man who sustained both a head injury and a stroke. Manly (2003) discusses the targeting of functional goals in treatment. Williams (2003) says goal setting procedures are one of the main components of programmes dealing with cognitive and emotional disorders. Almost every British rehabilitation centre follows a goal planning approach (Wilson \& Sopena 2005) .

\section{Cognitive, emotional and psychosocial deficits are interlinked}

Although cognitive deficits are, perhaps, the major focus of neuropsychological rehabilitation, there is a growing awareness that the emotional and psychosocial consequences of brain injury need to be addressed in rehabilitation programmes. Furthermore, it is not always easy to separate these out from one another. Not only does emotion affect how we think and how we behave, cognitive deficits can be exacerbated by emotional distress and can cause apparent behaviour problems. Psychosocial difficulties can also result in increased emotional and behavioural problems and anxiety can reduce the effectiveness of our intervention programmes. There is clearly an interaction between all these aspects of human functioning as recognised by those who argue for the holistic approach to brain injury rehabilitation. This approach, pioneered by Diller (1976) , Ben-Yishay (1978) and Prigatano (1986), is committed to the belief that the cognitive, psychiatric and functional aspects of brain injury should not be separated from emotions, feelings and self-esteem. Holistic programmes include group and individual therapy in which patients are encouraged to be more aware of their strengths and weaknesses, helped to understand and accept these, given strategies to compensate for cognitive difficulties and offered vocational guidance and support. Prigatano (1994) suggests that such programmes appear to result in less emotional distress, increased self-esteem and greater productivity. Prigatano (1999) and (Sohlberg and Mateer (2001) both describe the importance of dealing with the cognitive, emotional and psychosocial consequences of brain injury. Wilson et al. (2000) present a British holistic programme based on the principles of Ben-Yishay (1978) and Prigatano (1986). This is the Oliver Zangwill Centre for Neuropsychological Rehabilitation in Ely, Cambridgeshire. Although, these programmes appear to be expensive in the short term, they are probably cost-effective in the long term (see Wilson \& Evans 2002 and Prigatano \& Pliskin 2002).

Williams (2003) is concerned with the rehabilitation of emotional disorders following brain injury; he says that survivors are at particular risk of developing mood disorders. He goes on to say that this area is one of the key areas for development in neurological services. Behaviour disorders are targeted by Alderman (2003) . He works in a unit that treats some of the most severely disturbed brain injured people in the United Kingdom.

\section{Technology in rehabilitation}

The increasing use of sophisticated technology such as Positron Emission Tomography and Functional Magnetic Resonance Imaging is enhancing our understanding of brain damage (see, for example, Menon et al. 1998). To what extent these methods can improve our rehabilitation programmes remains to be seen. What is clear is the value of technology for reducing everyday problems of people with neurological damage. One of the major themes in rehabilitation is the adaptation of technology for the benefit of people with cognitive impairments. Computers, for example, may be used as cognitive prosthetics, as compensatory devices, 
as assessment tools or as a means for training. Given, the current expansion in information technology, this is likely to be an area of growth and increasing importance in the next decade. One of the earliest papers to use an electronic aid with a person with brain damage was Kurlychek (1983). This was important in that it tackled a real life problem as it was used to teach a man to check his timetable. In 1986 Glisky, Schacter, and Tulving taught memory impaired people computer terminology and one of their participants was able to find employment as a computer operator. Kirsch and his colleagues (Kirsch, Levine, Fallon-Krueger \& Jaros 1987) designed an interactive task guidance system to assist brain injured people perform functional tasks. Since then, there have been numerous papers reporting successful use of technology with brain injured people. A paper by Wilson, Emslie, Quirk, and Evans (2001) used a randomised control crossover design to demonstrate that it is possible to reduce the everyday problems of neurologically impaired people with memory and/or planning difficulties with a paging system.

Boake (2003) includes discussion of some of the early computer based cognitive rehabilitation programmes. Another area where technology is likely to play an increasing role in the future is Virtual Reality (VR) . VR can be used to simulate real life situations and thus be beneficial for both assessment and treatment. Rizzo, Schultheis, Kerns, and Mateer (2004) discuss VR in rehabilitation. This paper is in a special issue of Neuropsychological Rehabilitation focusing on technology in rehabilitation (Gregor \& Newell 2004).

\section{Rehabilitation begins in intensive care}

Perhaps one of the greatest changes in rehabilitation over the past few years has been in the assessment and management of people in states of reduced awareness i. e., those who are in coma or who are vegetative or who are minimally conscious (Coleman 2005, Jennett 2002). Jennett and Teasdale (1977), the authors and developers of The Glasgow Coma Scale (GCS-1977) define coma as "giving no verbal response, not obeying commands and not opening the eyes spontaneously or to stimulation” (p. 878) . The Royal College of Physicians Working Group report (1996) describes the characteristics of people in the vegetative state and Giacino et al. (2002) discuss the minimally conscious state. Since the Glasgow Coma Scale appeared over a quarter of a century ago, several other assessment tools have been developed to measure the behaviour of people in reduced states of awareness. One of the most recent is The Wessex Head Injury Matrix (WHIMShiel et al. 2000) . The WHIM can also be used to set goals for treatment. The goal planning approach is followed here in much the same way as described earlier with the exception that the client will not be able to participate in goal selection. The goals of course will be different from those set for people in the later stages of recovery. Whereas a rehabilitation goal for someone in a rehabilitation centre a year or two post injury might be to do with work or driving or using a compensatory system, the goal for someone just emerging from coma might be to increase eye contact or to establish a method of communication. The goals for this group of people might well be focussed on reducing impairments where the goals for people in the later stages are more likely to be with reducing handicap or increasing participation in society.

Shiel (2003) discusses rehabilitation of people in states of reduced awareness and presents four case studies to illustrate some of the principles involved. Andrews (2005) describes rehabilitation practice following profound brain damage and Elliott and Walker (2005) present rehabilitation interventions for vegetative and minimally conscious patients. 


\section{Neuropsychological rehabilitation is a field that needs a broad theoretical base}

Because people with brain injury are likely to face multiple difficulties including cognitive, social, emotional and behavioural problems, no one model or group of models is sufficient to deal with all these issues. In order to improve cognitive, social, emotional and behavioural functioning in everyday life we should not be constrained by one theoretical framework. Of the many theories that impact on rehabilitation, four areas are perhaps of particular importance, namely theories of cognitive functioning, of emotion, of behaviour and of learning. Consideration should also be given to theories of assessment, recovery and compensation. All the contributors to the Wilson (2003) book have tried to make clear how their clinical practice has been shaped by different theoretical models. Wilson (2002) argues for a broad based model and provides a recently published comprehensive model of rehabilitation. Boake (2003) describes the different methodologies that influenced some of the historical figures in the field. Manly (2003) refers to numerous theories of attention that have guided treatment approaches to this difficult area. Of several models of emotion, Williams (2003) is particularly influenced by Cognitive Behaviour Therapy which is certainly one of the most carefully worked out and clinically useful models of emotion at this time. The neurobehavioural model of Wood, 1987, 1990) is one that has influenced Alderman's work in his treatment of brain injured people with severe behaviour problems (Alderman 2003) . Finally, McMillan (2003) is concerned with the components and frameworks of service delivery for the rehabilitation of people with brain injury. Thus, it can be seen that ethical and effective neuropsychological rehabilitation requires a synthesis and integration of several frameworks, theories and methodologies to achieve its aims and ensure the best clinical practice.

\section{References}

1) Alderman, N. : Rehabilitation of behaviour disorders. In : Neuropsychological rehabilitation : Theory and practice (ed. B. A. Wilson) . Swets \& Zeitlinger, Lisse, The Netherlands, 2003, pp. 171-196.

2 ) Andrews, K. : Rehabilitation practice following profound brain damage. Neuropsychol. Rehabil., 15 : 461-472, 2005.

3 ) Ben-Yishay, Y. : Working approaches to remediation of cognitive deficits in brain damaged persons (Rehabilitation Monograph) . New York University Medical Center, New York, 1978.

4 ) Boake, C. : Stages in the history of neuropsychological rehabilitation. In : Neuropsychological rehabilitation : Theory and practice (ed. B. A. Wilson) . Swets \& Zeitlinger B. V., Lisse, The Netherlands, 2003, pp. 11-21.

$5)$ Clare, L. : Rehabilitation for people with dementia. In : Neuropsychological rehabilitation : Theory and practice (ed. B. A. Wilson). Swets \& Zeitlinger, Lisse, The Netherlands, 2003, pp. 197-215.

6 ) Coleman, M. : The assessment and rehabilitation of vegetative and minimally conscous patients. Neuropsychol. Rehabil., Special Edition, 15 : 161-162, 2005.

7 ) Diller, L. : A model for cognitive retraining in rehabilitation. The Clinical Psychologist, 29 : 13-15, 1976.

8 ) Elliott, L. \& Walker, L. : Rehabilitation interventions for vegetative and minimally conscious patients. Neuropsychol. Rehabil., 15 : 480-493, 2005.

9 ) Evans, J. J. : Rehabilitation of executive deficits. In : Neuropsychological rehabilitation : Theory and practice (ed. B. A. Wilson). Swets \& Zeitlinger, Lisse, The Netherlands, 2003, pp. 53-70. 
10) Giacino, J. T., Ashwal, S., Childs, N., et al. : The minimally conscious state : Definition and diagnostic criteria. Neurology, $58: 349-353,2002$.

11) Glisky, E. L., Schacter, D. L. \& Tulving, E. : Computer learning by memory impaired patients : Acquisition and retention of complex knowledge. Neuropsychologia, 24 : 313-328, 1986.

12) Gregor, P. \& Newell, A. : Neuropsychological Rehabilitation. Special issue on technology in cognitive rehabilitation. Psychology Press, Hove, 2004.

13) Houts, P. S. \& Scott, R. A. : Goal planning with developmentally disabled persons : Procedures for developing an individualized client plan. Department of Behavioral Science, Pennsylvania State University College of Medicine, Hershey, PA, 1975.

14) Jennett, B. : The Vegetative State : Medical facts, ethical and legal dilemmas. Cambridge University Press, Cambridge, 2002.

15) Jennett, B. \& Teasdale, G. : Aspects of coma after severe head injury. Lancet, $1: 878-881,1977$.

16) Kirsch, N. L., Levine, S. P., Fallon-Krueger, M., et al. : The microcomputer as an "orthotic" device for patients with cognitive deficits. J. Head Trauma Rehabil., $2: 77-86,1987$.

17) Kurlychek, R. T. : Use of a digital alarm chronograph as a memory aid in early dementia. Clin. Gerontol., $1: 93-$ 94, 1983.

18) Malec, J. F. : Goal attainment scaling in rehabilitation. Neuropsychol. Rehabil., 9 : 253-275, 1999.

19) Manly, T. : Rehabilitation for disorders of attention. In : Neuropsychological rehabilitation : Theory and practice (ed. B. A. Wilson). Swets \& Zeitlinger, Lisse, The Netherlands, 2003, pp. 23-52.

20) McLellan, D. L. : Functional recovery and the principles of disability medicine. In : Clinical neurology (eds. M. Swash \& J. Oxbury). Churchill Livingstone, Edinburgh, 1991, pp. 768-790.

21) McMillan, T. \& Sparkes, C. : Goal planning and neurorehabilitation : The Wolfson Neurorehabilitation Centre approach. Neuropsychol. Rehabil., 9 : 241-251, 1999.

22) McMillan, T. M. : Rehabilitation services and their delivery. In : Neuropsychological rehabilitation : Theory and practice (ed. B. A. Wilson). Swets \& Zeitlinger, Lisse, The Netherlands, 2003, pp. 271-291.

23) Menon, D. K., Owen, A. M., Williams, E. J., et al. : Cortical processing in the persistent vegetative state revealed by functional imaging. Lancet, $352: 200,1998$.

24) Poppelreuter, W. : Disturbances of lower and higher visual capacities caused by occiptal damage (Trans. J. Zihl \& L. Weiskrantz) . Clarendon Press, Oxford, 1917.

25) Prigatano, G. P. : Personality and psychosocial consequences of brain injury. In : Neuropsychological rehabilitation after brain injury (eds. G. P. Prigatano, D. J. Fordyce, H. K. Zeiner, et al.) . The Johns Hopkins University Press, Baltimore, London, 1986, pp. 29-50.

26) Prigatano, G. P. : Individuality, lesion location, and psychotherapy after brain injury. In : Brain injury and neuropsychological rehabilitation (eds. A.-L. Christensen \& B. P. Uzzell) . Lawrence Erlbaum Associates, Hillsdale, NJ, 1994, pp. 173-186.

27) Prigatano, G. P. : Principles of neuropsychological rehabilitation. Oxford University Press, New York, 1999.

28) Prigatano, G. P. \& Pliskin, N. H. : Clinical neuropsychology and cost outcome research : A beginning. Psychology Press, Hove, 2002.

29) Rizzo, A. A., Schultheis, M., Kerns, K. A., et al. : Analysis of assets for virtual reality applications in neuropsy- 
2006 年 6 月 30 日

chology. Neuropsychol. Rehabil., 14 : 207-239, 2004.

30) Royal College of Physicians Working Group : The permanent vegetative state. J. R. C. Physicians, 30 : 119-121, 1996.

31) Shiel, A. : Rehabilitation of people in states of reduced awareness. In : Neuropsychological rehabilitation : Theory and practice (ed. B. A. Wilson) . Swets \& Zeitlinger, Lisse, The Netherlands, 2003, pp. 253-269.

32) Shiel, A., Horn, S. A., Wilson, B. A., et al. : The Wessex Head Injury Matrix (WHIM) main scale : A preliminary report on a scale to assess and monitor patient recovery after severe head injury. Clin. Rehabil., $14: 408^{-416 \text {, }}$ 2000.

33) Sohlberg, M. M. \& Mateer, C. A. : Cognitive rehabilitation : An integrative neuropsychological approach. Guilford Press, New York, 2001.

34) Tate, R. L., Strettles, B. \& Osoteo, T. : Enhancing outcomes after traumatic brain injury : A social rehabilitation approach. In : Neuropsychological rehabilitation : Theory and practice (ed. B. A. Wilson). Swets \& Zeitlinger, Lisse, The Netherlands, 2003, pp. 137-169.

35) Williams, W. H. : Neuro-rehabilitation and cognitive behaviour therapy for emotional disorders in acquired brain injury. In : Neuropsychological rehabilitation : Theory and practice (ed. B. A. Wilson). Swets \& Zeitlinger, Lisse, The Netherlands, 2003, pp. 115-136.

36) Wilson, B. A. : Towards a comprehensive model of cognitive rehabilitation. Neuropsychol. Rehabil., 12 : 97-110, 2002.

37) Wilson, B. A., Emslie, H. C., Quirk, K., et al. : Reducing everyday memory and planning problems by means of a paging system : A randomised control crossover study. J. Neurol. Neurosurg. Psychiatry, 70 : 477-482, 2001.

38) Wilson, B. A., Evans, J., Brentnall, S., et al. : The Oliver Zangwill Centre for Neuropsychological Rehabilitation : A partnership between health care and rehabilitation research. In : International handbook of neuropsychological rehabilitation (eds. A.-L. Christensen \& B. P. Uzzell) . Kluwer Academic/Plenum Publishers, New York, 2000, pp. 231-246.

39) Wilson, B. A. \& Evans, J. J. : Does cognitive rehabilitation work? Clinical and economic considerations and outcomes. In : Clinical neuropsychology and cost-outcome research : An introduction (ed. G. Prigatano) . Psychology Press, Hove, 2002, pp. 329-349.

40) Wilson, B. A., Evans, J. J. \& Keohane, C. : Cognitive rehabilitation : A goal-planning approach. J. Head Trauma Rehabil., $17: 542-555,2002$.

41) Wilson, B. A. \& Sopena, S. : The practice of neuropsychological rehabilitation. Brain Impairment, $6: 117-118$ (abstract) , 2005.

42) Wood, R. L. : Brain injury rehabilitation : A neurobehavioural approach. Croom Helm, London, 1987.

43) Wood, R. L. : Neurobehavioural sequelae of traumatic brain injury. Taylor \& Francis, London, 1990.

44) Ylvisaker, M. \& Feeney, T. : Reconstruction of identity after brain injury. Brain Impairment, 1: 12-28, 2000. 